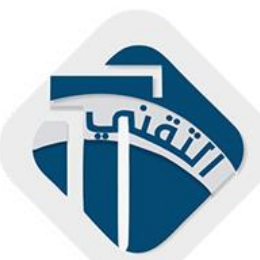

مجلة التقني

http://journal.mtu.edu.iq الموقع الالكتروني

مقاله بحثيه

الاشتراطات التصميمية للأعلان على أقمشة الازياء المطبوعة لشركة موسكينو ميلانو

الإيطالية

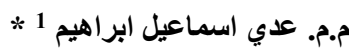

كلية الفنون التطبيقية, الجامعة التقنية الوسطى, بغداد, العر اق

oday.ismael@mtu.edu.iq : البريد الإلكتروني *

\begin{tabular}{|c|c|}
\hline الخلاصة & معلومات المقالة \\
\hline يعد تصميم الأقمشة و الازياء فناً أبتكاريا يتصف بسمات وظيفية وجمالية, يخوض فيها المصمم لإحداث اكبر اثر في الملتقي و على قناعته الذوقية والجمالية & تاريخ الاستلام \\
\hline حيث تلعب القيم الجمالية الى جانب القيمة الوظيفية التي يتاسس التصميم لغرضها معا دور ا في تلبية متطلبات العصر وسد احتباجات المستهلك حيث نلاحظ & 26 تموز 2020 \\
\hline اليوم ازدياد الطلب على اقتناء الأقشة والازياء التي تم التوصل الى مر احلها النهائية من خلال التطور التقني, و التقنيات التي كانت مو اكبة لحركة التطور & تاريخ القبول \\
\hline الذي ماز ال يتطور ويتنوع وحسب الحاجة العصرية, أن الاعلان يختلف باختلافات كثيرة من حيث التطبيق و الوسائل, و اخذت تصـاميم الاعلانات تتتشر & ل ل \\
\hline منها على الورق و الجدران و المجلات و الجر ائد وسائل النقل وايضا انتشرت على أقشة الازياء, و هو في كل حال من هذه الحالات يحاول أن يقترب في & 9 يليون $20<0$ \\
\hline تحقيق أهدافه, وهو تحقيق الاتصسال بأيصال الرسالة الى المتلقين, فضلاً عن تحقيق الترويج و الهدف في ايصال المعنى الجمالي و الوظيفي للاقمشة و الازياء & تاريخ النشر \\
\hline ظهور علاقات تصميمية متداخلة مع بنية الزي و التي ارتبطت كلياً مع قدرات محتوى الفكرة التصميمية حيث تشكل حركه داخل فضاء بنية الزي مما أدى. & 30 ايلول 2020 \\
\hline الى لفت الانتباه و الجذب البصري ـ اظهرت الفكرة الرئيسية لمادة الاعلان المطبوع غالباً من المجتمع المقصود بالاعلان, و المصمم هو جزء منـه وينتمي & \\
\hline الى مرجعياته الثقافية و الاجتماعية والعقائدية، فكثيراً ما يعبر المصمح عن (المكان) باختبار الرموز والالوان المعينـة تفي بـالغرض منها في تحديد الهدف & \\
\hline و الوظيفة . ظهرت قدرة مصمم الاقمشة و الازياء في بناء موضوع الاعلان وتجسيده على فضاء بنية الزي، وذلك لألمامه بـالاطر الموضوعية (الفكريـة) & \\
\hline و التقنية (الاخر اجية) ودوره في تعزيز الهذف المطلوب في بناء الاعلان وايصال الافكار بطريقة ذكية ومؤثرة . ووضع الباحث أهم الاشتر اطات للأعلان & \\
\hline على أقمشة الازياء المطبو عة اهمها اظهار المز اياو التأثير ات البيئية العر اقية كمرنكزات في تصميم الاعلان المطبو ع على الاقشة العر اقية المعاصرة . & \\
\hline
\end{tabular}

الكلمات المفتاحبة : الأشتر اطات, التصميمية, الاعلان, اقشة الازياء المطبو عة

\title{
Design requirements for advertising on fashion fabrics printed for the Italian company Moschino Milano
}

\section{Oday Ismael Ibrahim}

College of Applied Arts, Middle Technical University, Baghdad, Iraq

*Corresponding author E-mail: oday.ismael@mtu.edu.iq 
Article history:

Received

26 July 2020

Accepted

9 September 2020

Published

30 September 2020

\section{Abstract}

The design of fabrics and fashion is an innovative art characterized by functional and aesthetic features, in which the designer strives to make the biggest impact on the forum and its aesthetic and aesthetic conviction. The aesthetic values, together with the functional value that the design is based on, play a role in meeting the requirements of the age and filling the needs of the consumer. The acquisition of fabrics and fashion which has reached its final stages through the technical development, and the technologies that were keeping pace with the movement of development, which is still evolving and varies according to the modern need, that the declaration differs in many differences in terms of application and means ., Advertising in newspapers, walls, magazines, newspapers, transport and also spread to fashion fabrics, which in each of these cases is trying to come close to achieving its objectives, namely to achieve contact with the delivery of the message to the recipients, as well as the promotion and objective in conveying the aesthetic and functional meaning of fabrics and fashion, A set of conclusions and conclusions were reached

Keywords: requirements, Design, advertising, printed fabrics

الفصل الاول/ مشكلة البحث والحاجة اليه

1-1

أن الإعلانات بشكل عام ومنها الخاصة بأقشة الازياء المطبو عة تعمل على تعريف المتلقي بالمنتوج و العمل على أقناعة لكونها لغة تخاطب و عنصر جذب بما تحملة من قيم

تعبيرية يتحكم من خلالها مصمم الاقمشة لتحقيق فاعلية الوظيفة والاتصال ثم الاستجابة لدى المتلقي, وعلى وفق اطار اشتر اطية التصميم الذي يعتمدها المصمم المبدع بما يمتلكه من

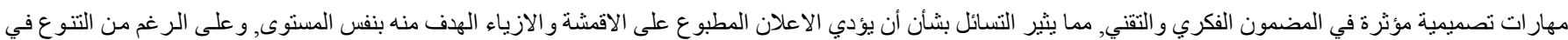
مادة التطبيق وأمكانية أن يؤدي نفس التصميم هدفه عند تطبيقه على أي مجال أعلاني آخر , وهنا يثير البحث تساؤلا يبين من خلاله مشكلة البحث :

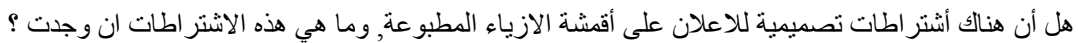

1-2 أهمية البحث :

وقد يسهم البحث في تنمية الوعي المعرفي للباحثين و التقنيين و الفنيين فضلا عن إرساء الاشتر اطات التصميمية ووضعها إمام المختصين من مصممي الأقمشة و الازياء لغرض استلهام

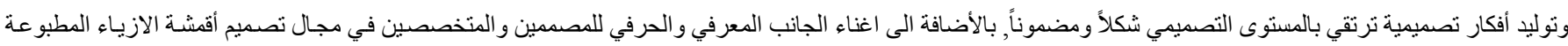
وتقنيات الاعلان, وذللك من خلال اختيار أزياء و تصاميم ( شركة موسكينوميلانو الأبطالية ), حيث يعود سبب اختبار ها إلى تميز هـا بتصاميم اعلانية والتي تخدم هذا البحث من حيث الفكرة المقدمة وتتوع موضو عاتها ووظيفتها, كما ان سنة (2016) تميزت بأنتاج ازياء متنو عه استخدمت الثركه اعلاه الجانب الاعلاني و الترويجي في تصاميمها . -1 - التعرف على الاشتر اطات التصميمية للأعلان على أقشة الازياء المطبو عة لشركة موسكينو ميلانو.

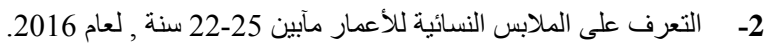
1-4 حلود البحث : 1 - 1 الحدود الموضوعية:- تصاميم شركة موسكينو ميلانو الإيطالية. 2-2 - الحدود المكانية :- الملابس النسائية للأعمار مآبين 25-22 سنة. 3 - 3 - 2015 الحدود الزمانية: سنة 2015 
الإعلان هو احد وسائل الاتصال الفعالة، إلا أن تللك الوسيلة قد زادت الحاجه إليها وز اد استخدامهاوتعددت أساليبها وطرقها، وبازدياد الحاجه إليها تطورت تقنياتها الطباعية و الفوتو غر افية و النسيجية على المستوى النظري و العملي ، و هذا التطور قد غير الكثير من مستو اها الوظيفي لتحقيق أهدافها الاتصالية ومن ثم تحقيق هدفها بطريقة فعالة وصحيحة, ولو ولون تتبعنا تاريخياً موضو ع الإعلان لوجدناه قد بدأ أولى مر احل حياة الانسان, عندما بدأ يضع الرموز على جدران الكهوف, بوصفها وهئ علامات دالة ومرشده لمكانه وطريق مروره أو أب مكان يعتبر الإعلان أداة مهمة ومؤثّرة في العمليات التجارية المختلفة، وهو وسيلة التسويق الأولى والأقوى للمنتجات والخدمات المختلفة، والإعلان يشتمل على كل الوسائل الإعلانية التي يمكن استخدامها من أجل تسويق السلع و المنتجات. " الإعلان نشاط للاتصال اللاشخصىى، و التفاعلى ، بمارس لحساب معلن معلى معين مقابل ثمن معلوم، لأجل نقل رسالة عبر وسائط اتصـال مختارة إلى جمهور مستهدف، بهدف استثارة فعل معين، يحقق منفعة للمعلن".[4] وعرفتة جرجيس بأنة : " جهد اتصالي مخطط على اساس علمية وعملية ويركز على استخدام مدخل

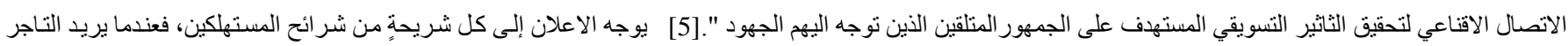

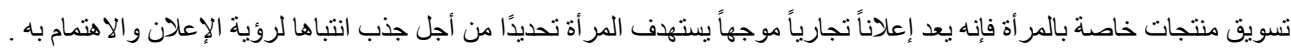

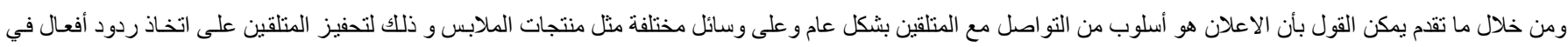

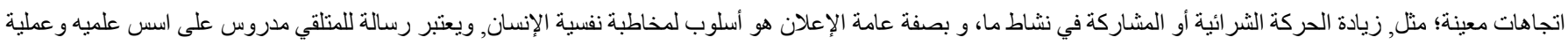

بهدف استثار ته ليحقق منفعة للجهة المعلنة .

\section{2-1-2 اهمبة الاعلان}

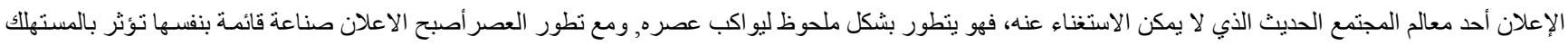

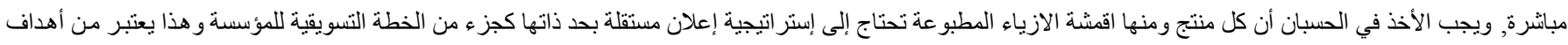

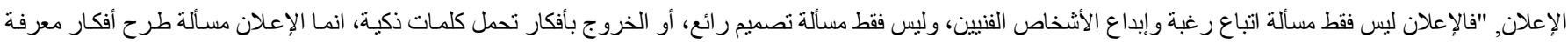
مسبقاً بطريقة فعالة على أساس جذب و اكتساب منلقين من الناس في مو اقع معرفة مسبقاً، وحثهم على ردات فعل بطريقة معينة مطلوبة "[6].

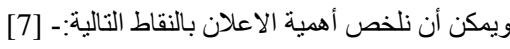
1- الترويج للسلع و الخدمات و الأفكار بأيسر السبل و أقل التكاليف, وذلك بعد أن يختار الوسيلة الإعلانية التي يريدها, ومنها الاعلان على اقمشة الازياء .

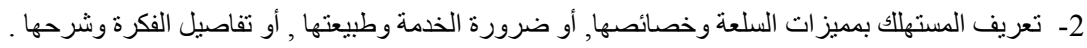

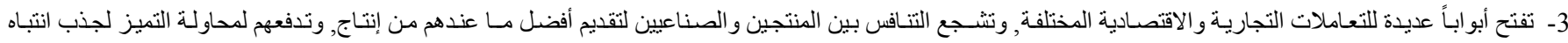
المستهلكين. بات استخدام الثركات الاعلانية للملابس بمختلف انو اعها, فلم يقتصر الاعلان فيها على البضائع والسلع لغرض كسب المتلقين وزيادة المبيعات, بل القيام بوظيفة التوعية لخطر ما,

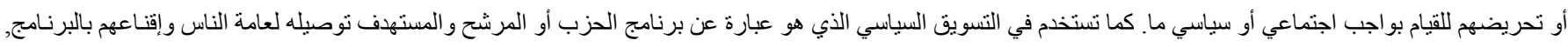
أي إحداث التأثير المستهدف على الر أي العام للناخبين .

3-1-2

للاعلان خصائص يشترط تحققها في مضمون الاعلان ليتميز عن غيره من انشطة الترويج, فضلاً عن ان الاعلان " وسيلة للاتصسال مزدوج الاتجاه، بمعنى أن المعلن لا يكتفي

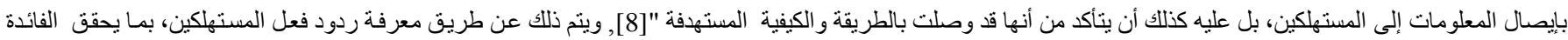

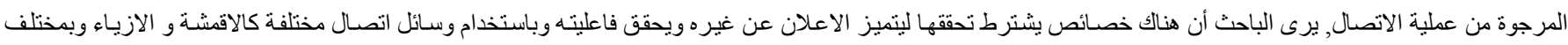

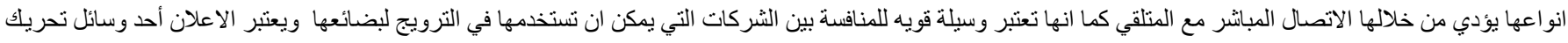

الطلب, وفي حالات نادرة جدا يمكن أن يكون هو الوسيلة الوحيدة في تحريك الطلب خلال مدة زمنية معينة وتشير هذه الحقيقة إلى صعوبة تقويم فاعلية الاعلان, أنظرمخطط رقم (1) ـ 


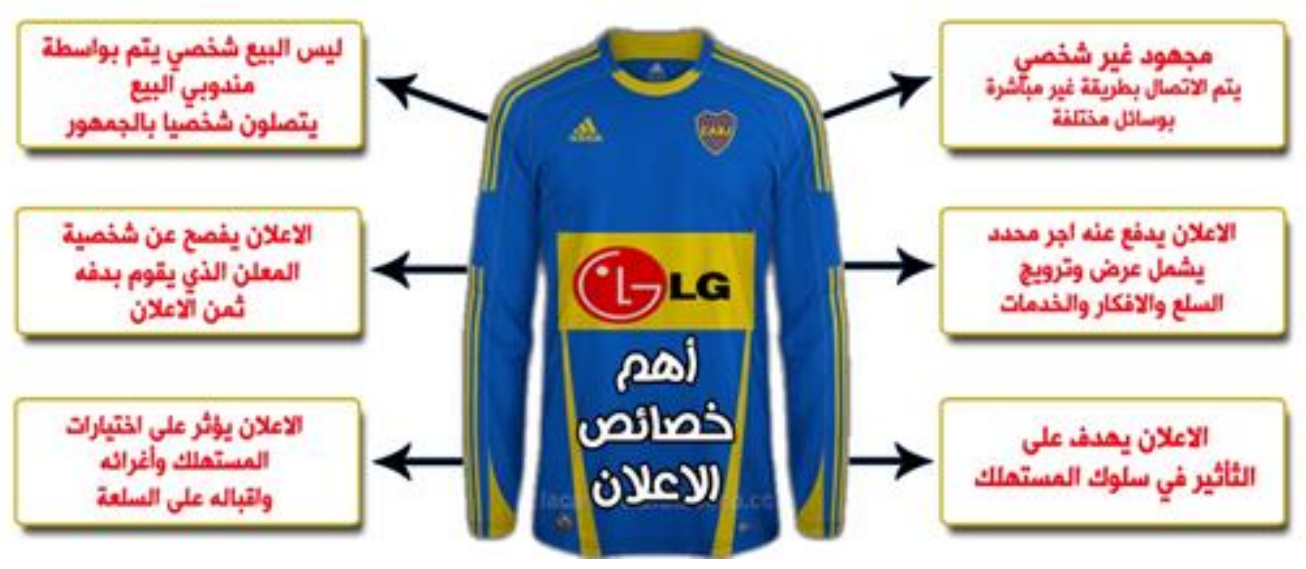

مخطط رقم (1) يمثل أهم الخصائص التي يجب توفرها بالأعلان

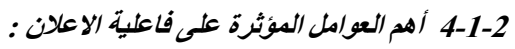

هناك عو امل يكون تاثير ها على مدى مقبولية الاعلان وبغض النظر عن الوسيلة المستخدمه بالاعلان , و هذه العو امل تلعب دور ا كبير ا وفاعلا مؤثر ا في نجاح او فثل الاعلان, كما انها تعطي الاعلان القوة و التو اصل مع المستهلكين, وان اختيار الزي و اعتمادة كوسيلة أعلانية مع نوظيف الاعلان على بنية الزي تجعل منه وسيلة ترويجية مهمه نو اكب الحداثة و التطور التقني ـ والمخطط رقم (2) يوضح أهم العو امل المؤثره غلى فاعلية الاعلان :-

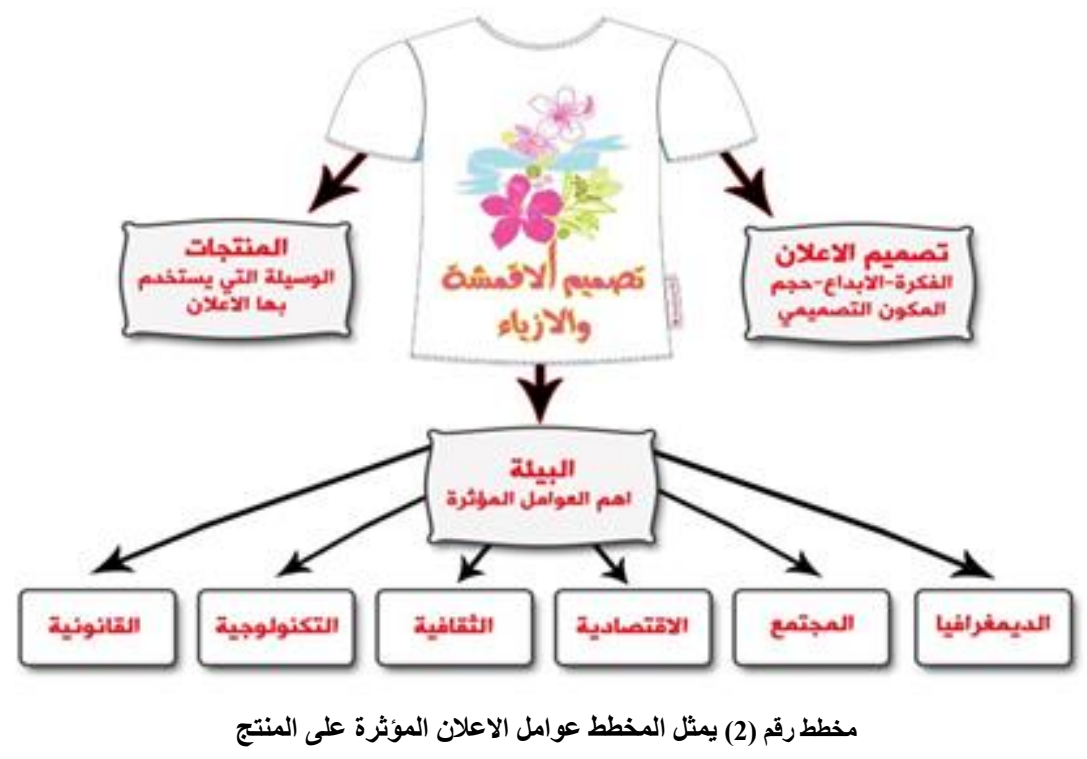

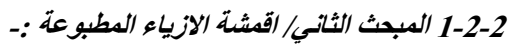

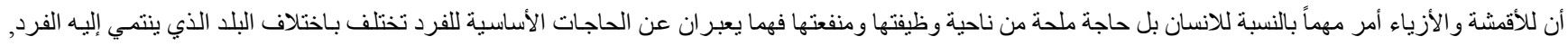

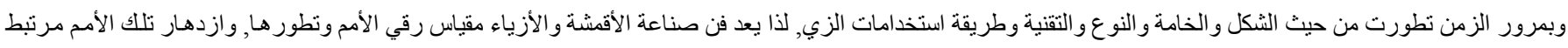

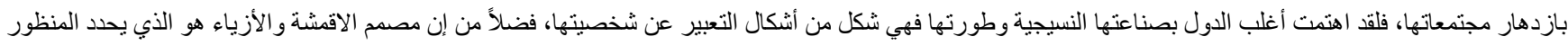
الجمالي ونوع الأسلوب المتبع و الكيفيات التي يخلقها لإعادة ترتيب أنتكال التصميم حنى يحقق الجو انب الجمالية و التعبيرية و الأتصالية وبما ينسجم مع الوظيفة . " يعتمد تصميم الأقمشـة

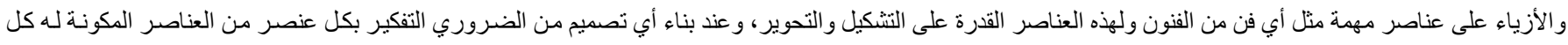

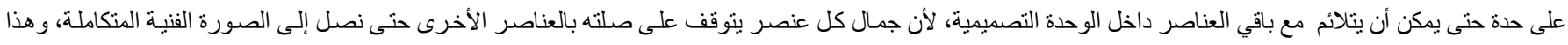

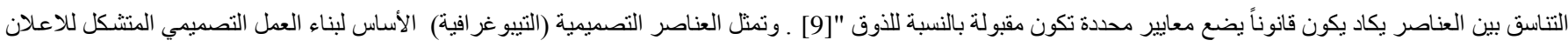


Oday Ismael Ibrahim, Journal of Techniques, Vol. 2, No. 3, September 30, 2020, Pages 28-43

على بنية الزي الذي يمثل وسيلة من الوسائل الوظيفية والاتصالية، ويطلق عليها العناصر السلسة لمـا لها من القدرة على التحول و التنشكل, إذ ترتبط مع بعضهـا البعض داخل التكوين

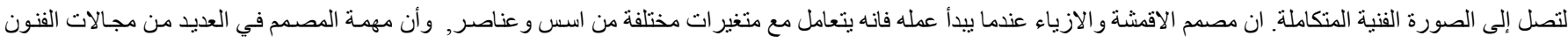

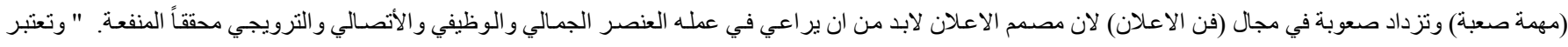
مرحلة تصميم الاعلان على (الاقمة والازياء) وتنفيذها الركيزة الاساسية في تحقيق النجاح المستهدف لاي حملة اعلانية باستخدام الاسس و العناصر الفنية, مما يؤدي الى قيام الاعلان

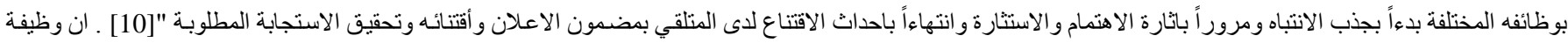

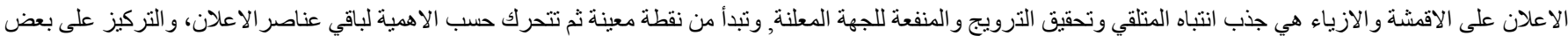

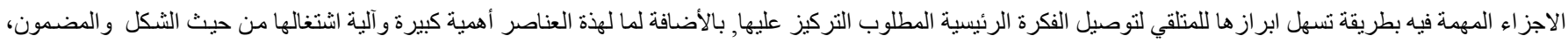

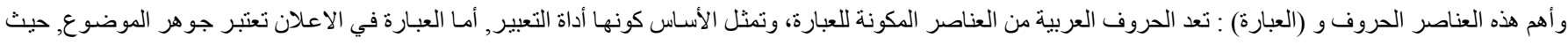

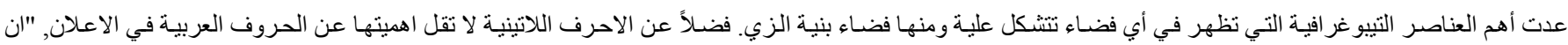
التيبوغر افيا ماهي الا سلسلة من التفاعلات مابين اليد، والآلة، العضوي والهندسي، الجسم البشري و النظام التجريدي، حتى ان فناني عصر النهضـة حاولو ا ان يطبقو ا معاييرنسب جسم

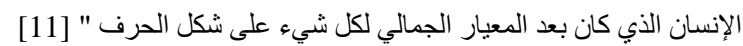
ومن خلال ما تقدم يمكن القون ان الحرف المكون للعبارة سواء كان (عربياً أو لاتينياً ) والذي يتشكل بتشكيلات تصميمية يمكن جعلة كنقطه جذب ولفت التهب انتباة المتلقين في الاعلان

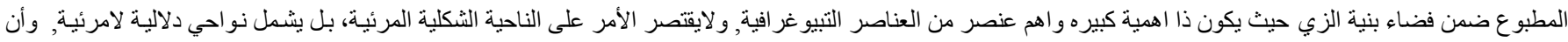

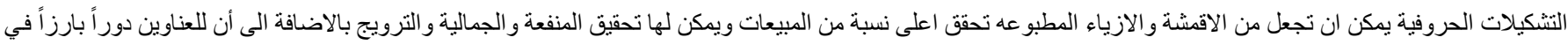

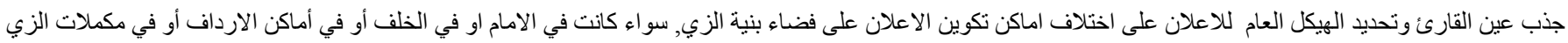

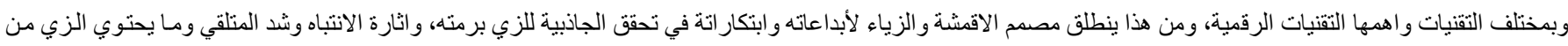

. تصاميم.

تحقق التقنية الرقمية باستخدام بر امج معالجة الكلمات والصور اضـافة العديد من التأثير ات عليها, مما يسـاعد في ابر از المعنى او تحقيق السيادة لتلك الكلمات بالنسبة الى بـاقي

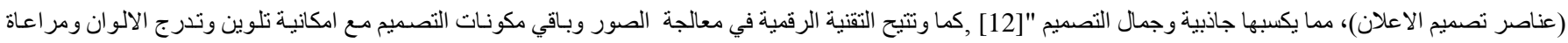

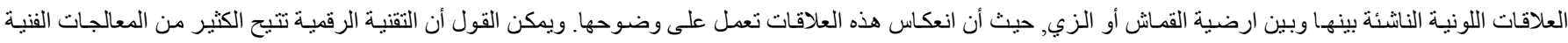

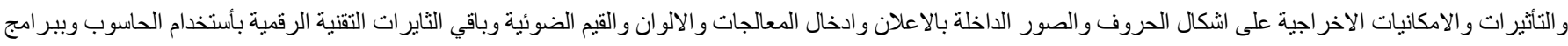

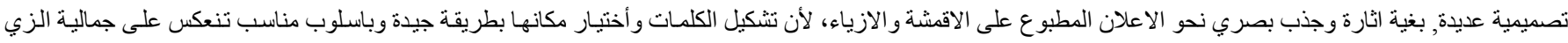

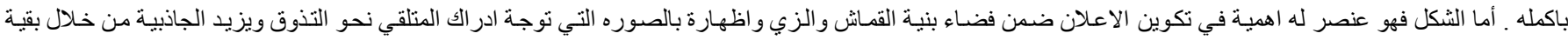

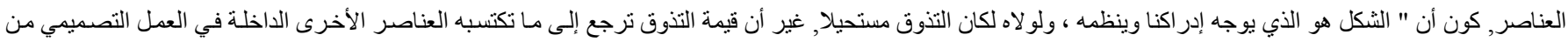
حيو و و إثارة حين ينظمها الثكل, فالشكل لا يجعل من هذه العناصر مفهومة فحسب، بل هو يزيد من جاذبيتها ويؤكدها " [13], فهو ينظم العناصر من خلال تجميعه لها في أبعاده ولونـه

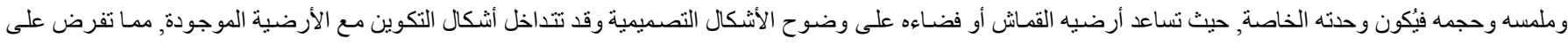

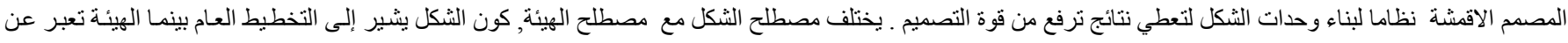
المظهر الخارجي للشكل " وبهذا فقد مبز ارنهايم (Arinheim) الثكل على أنة الهيئة مع إضافة المعنى والمضمون " [14], مما يؤدي بمصم الاقمشة والازياء على إيجاد التوازن بين

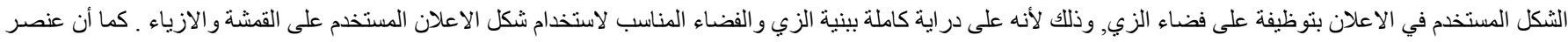

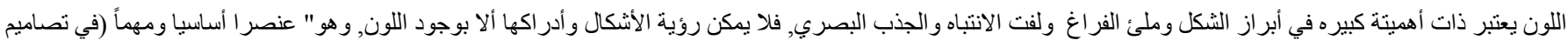
الاعلان المطبوع على الاقمشة والازياء) فهو يعزز الثكل ويحقق حيزا نفسيا وماديا للعمل الفني (الأعلاني)، ويعد من أهم العناصر أو الصفات الإدر اكية المرتبطة بتلازم فاعل ميع بقية

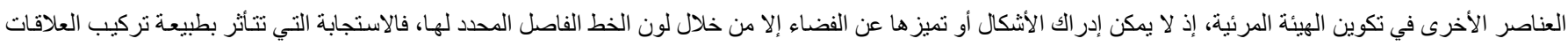
اللونية و الثكلية للأشكال و أنماطها والمساحات التي تحتلها و القدرة التعبيرية التي تسبطر على توجيهها لدعم الفكرة التصميمية"[15], حيث بعتمد مصم الاقمشة والازياء على اللون في

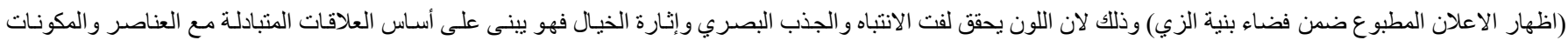

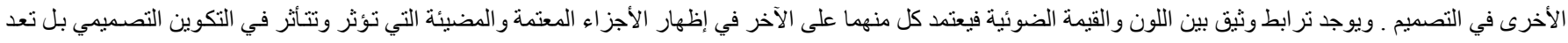

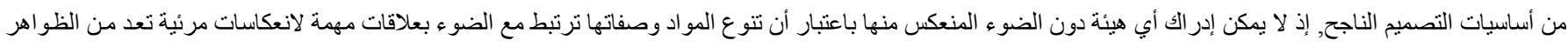

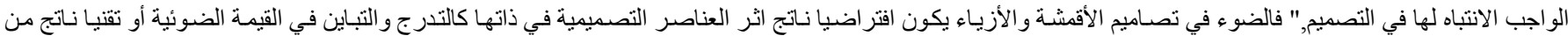

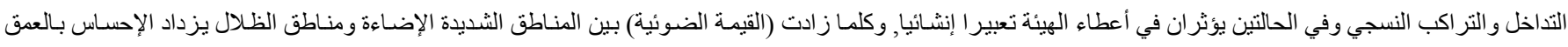

الفضائي"[16], و عليه بعالج مصمم الاقشة و الازياء الأشكال الفاتحة والقاتمة بما يناسب أهداف الاعلان المطبوع على الاقمشة وبنية الزي، إذ يوجه رؤية المتلقي من جزء لآخر أو

أبر از شكل معين دون شكل أخر و هذا يطلب الموازنة بين القيم الضوئية وترتيبها وتنظيمها ـ ويستنتج الباحث من ذلك بان هذه العناصر لها اهمية كبيره في تصميم الاعلان الترويجي المطبوع ضمن فضاء بنية الزي, وأن على المصم ان ير اعي في عمله عنصرين اساسيين في وقت واحد هـا: العنصر الجمالي و العنصر الوظيفي, الذان يحققان هدفاً (منفعة) وهو 
Oday Ismael Ibrahim, Journal of Techniques, Vol. 2, No. 3, September 30, 2020, Pages 28-43

الترويج , لان الاعلان ليس لوحة جمالية فقطو انما هو لوحة جمالية تؤدي هدفاً وظيفياً محدداً وتخاطب مجموعات غير متجانسة من المتلقين لاقتاعهم عقلياً ووجدانياً بفكرة تسويقية محددة ومدروسة, ضمن وسيلة اتصالية وهي الأقمشة و الازياء.

2-2-2

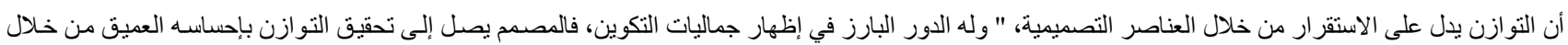

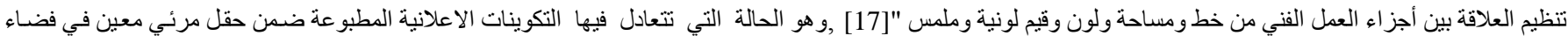

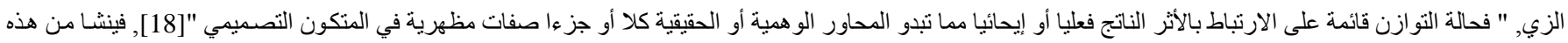

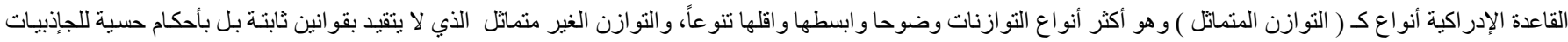

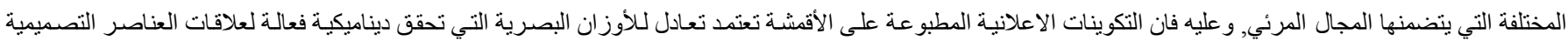
وترتيها ضمن تصميم بنية الزي. أما الانسجام فأنة يستند على التو افق أو التقارب بين أنشكال العناصر في صفة واحدة, أو مجموعة الصفات الثكلية أو اللونية أو الحجوم أو تقارب التبات

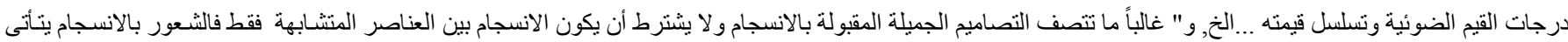

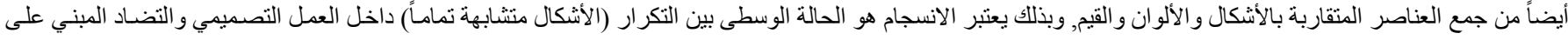

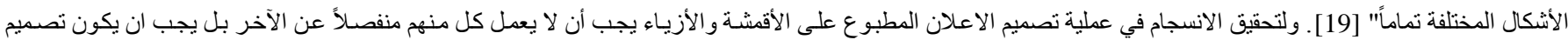

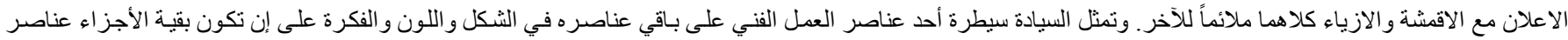

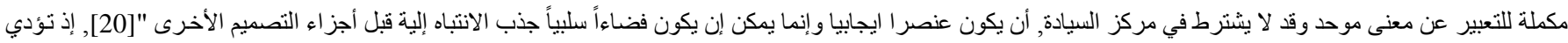

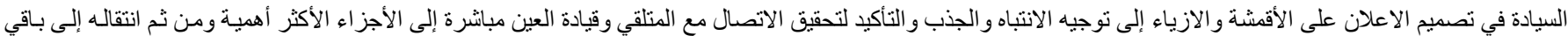

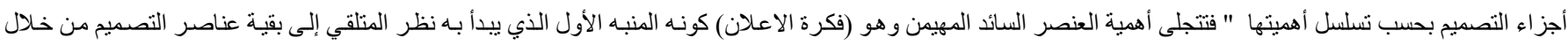

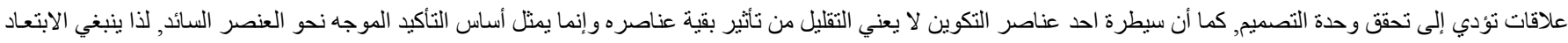

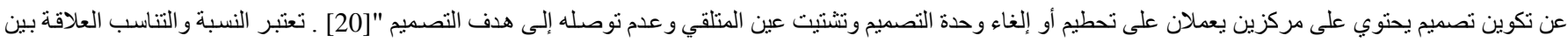

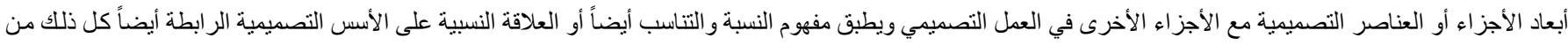
أجل الحصول على جمع لعناصر متعددة تختلف أبعادها (حجماً أو مساحة) ولوناً وشكلاً وملمساً واتجاهاً، من أجل الحصول على تكوينات منظمة تتنتمل على الوحدة في الكل العام دون

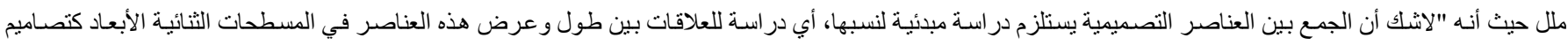
الأقشة، أو العلاقات بين الحجوم في الأجسام الثلاثية الأبعاد كتصاميم الأزياء للأجسام البشرية، كما تتطلب در اسة لنسب المسافات الفاصلة بين كل منها لتخلق إيقاعات مقبولة جمالياً"

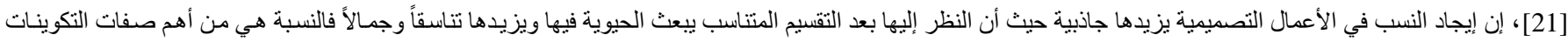
الطبيعبة حيث نر اها واضحة في كثير من الأشياء.

هذا يؤكد على أهمية وضرورة معرفة النسب الصحيحة لجسم الإنسان و أثر حركة الأجسام على تصاميم الأزياء وفيما يلي أكثر ما يهم مصمم الأزياء في هذا المجال:[22] - أن هناك علاقة كبيرة ومهمة بين نسب الجسم وحركة أجزائه المتغيرة التي تتناسب مع باقي أجز اء الجسم.

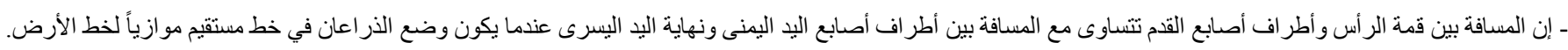
- حركة الذراع تؤدي إلى تغيير في شكل الكتف.

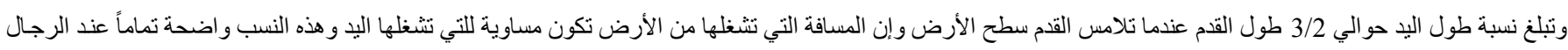
وتقل قليلاً عند النساء ـ ونوزيعات النسب عموماً تؤكد على عملية التناسب بين الأجز اء مع بعضهاو ومع الكل العام ويتم ذلك بملاءمهة الخطوط الموضو عة بحيث تناسب اللون والمادة

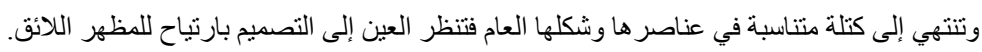
أن في أغلب الأحيان أن للأسس و علاقاتها البصرية تنشط وتفعل مبدأين هما: (التكر ار و التباين) اللذان يكونـان الإيقاع ويعد " التكرار مهماً في تصميم وطباعة الاقمشة، و غالباً

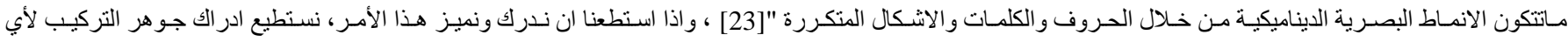
منجزتصميمي. ويعد التكر ار من الأسس البنائية المهمة في التصميم التيبوغر افيكي، فمن خلاله يتتم تكوين أنواع بصرية ممتدة ،ديناميكية وايقاعية، " ويشبر إلى مظاهر الامتداد

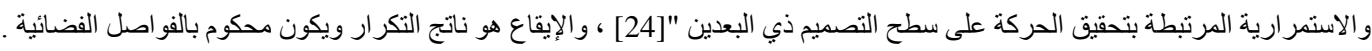
ومن خلال توجيه للاسس المرئية وبطريقة ديناميكية ينتج عنها حركة بصرية (تتشط داخل الاعلان المطبوع ضدمن فضساء الزي) ومن خلالها تساهم في تنقل العين عبر حركة

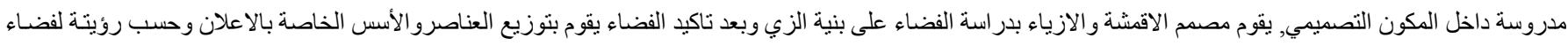
الزي بحيث يقوم بتز اوجها مع ارضية الزي, "ومن خلال التأكيد أو التركيز أكثر على جو انب معينة داخل العمل الفني والتأكيد بدرجة أقل على جو انب أخرى يضع الفنان أسس المر اكز

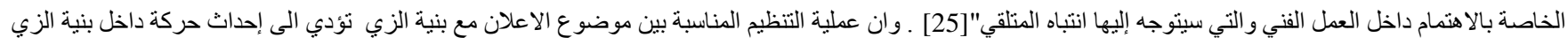


و هذة تؤدي الى تحقيق جذب المتلقي للاعلان المطبوع على الاقمشة والازياء . كما ان اعطاء السيادة لفكرة الاعلان وجعلها في المكان المناسب ضمن فضاء بنية الزي تجعل عين المتلقي تتطلق منها الى باقي اجز اء الاعلان المطبوع على على اقمشة الازياء .

المبحث الثالث/ الازياء وسيلة أتصالية 1-3-2 الاتصال.. وأهم العناصر الاتصالية:-

الأتصال هو لغة مشتركة للتفاهم وتبادل الأفكار و الار اء مع الآخرين, اذ يعد من الممارسات والانشطة الانسانية قديما ولا يز ال لوقتنا هذا, و هو التفاعل الذي يحصل بين طرفين

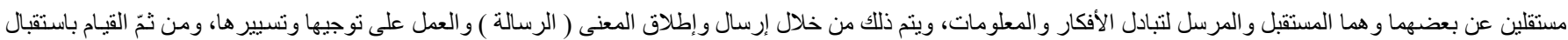
هذه الرسالة، وتكوين استجابة في بيئة ووسط اجتماعي محدد, و الأتصال هو " العملية التي يتم بو اسطتها نقل المعلومات والأفكار و التوجيهات من خـلال نظام اجتماعي و الطرق التي

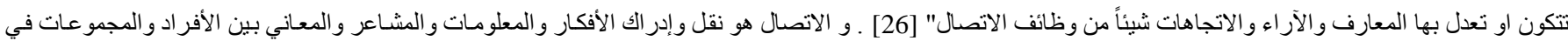
مجتمع ما بطرق ووسائل كثيرة منها اقشة الازياء المطبوعة, "الاتصال نشاط يستهدف العمومية والذيوع و الانتشار عن طريق انتقال المعلومات او الافكار او الآراء او الاتجاهات من

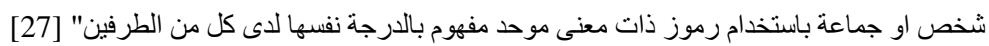
و الاتصال يرتبط بمفهوم الإعلام ارتباطاً وظيفياً بالمعنى كمفهوم عام يتداخل معه في كثير الأحيان " و هناك تقسيم رئيسي للإعلام على أساس طبيعته الاتصالية، فيقسم الى نوعين

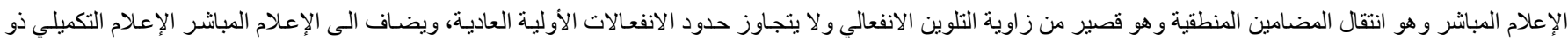

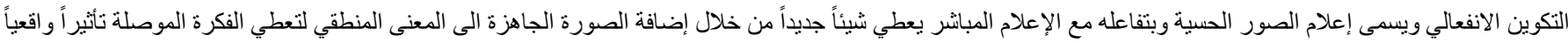

حياً " [28] ]

والاتصال يؤكد على أمرين أساسيين :" الأول ينعلق باستعمال نظام من الرموز يتعارف الناس على قبول معانيها لتعني للجميع شيئًاً محدداً ذو دلالة ومتعارف عليه اجتماعياً. والأمر الثاني يتعلق بتبادل المعاني، أي أن تبادل

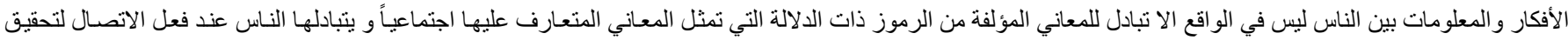
التفاهم بينهم، وعلى هذا الاساس يمكن بجمع وترتيب هذه الرموز ضمن نظام محدد قابل للتفسير ان يؤدي إلى و لادة معناً محدداً، وتحقق أتصـال المرسل بالمتلقي، وتجعل من تبادل

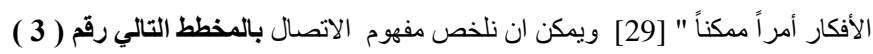

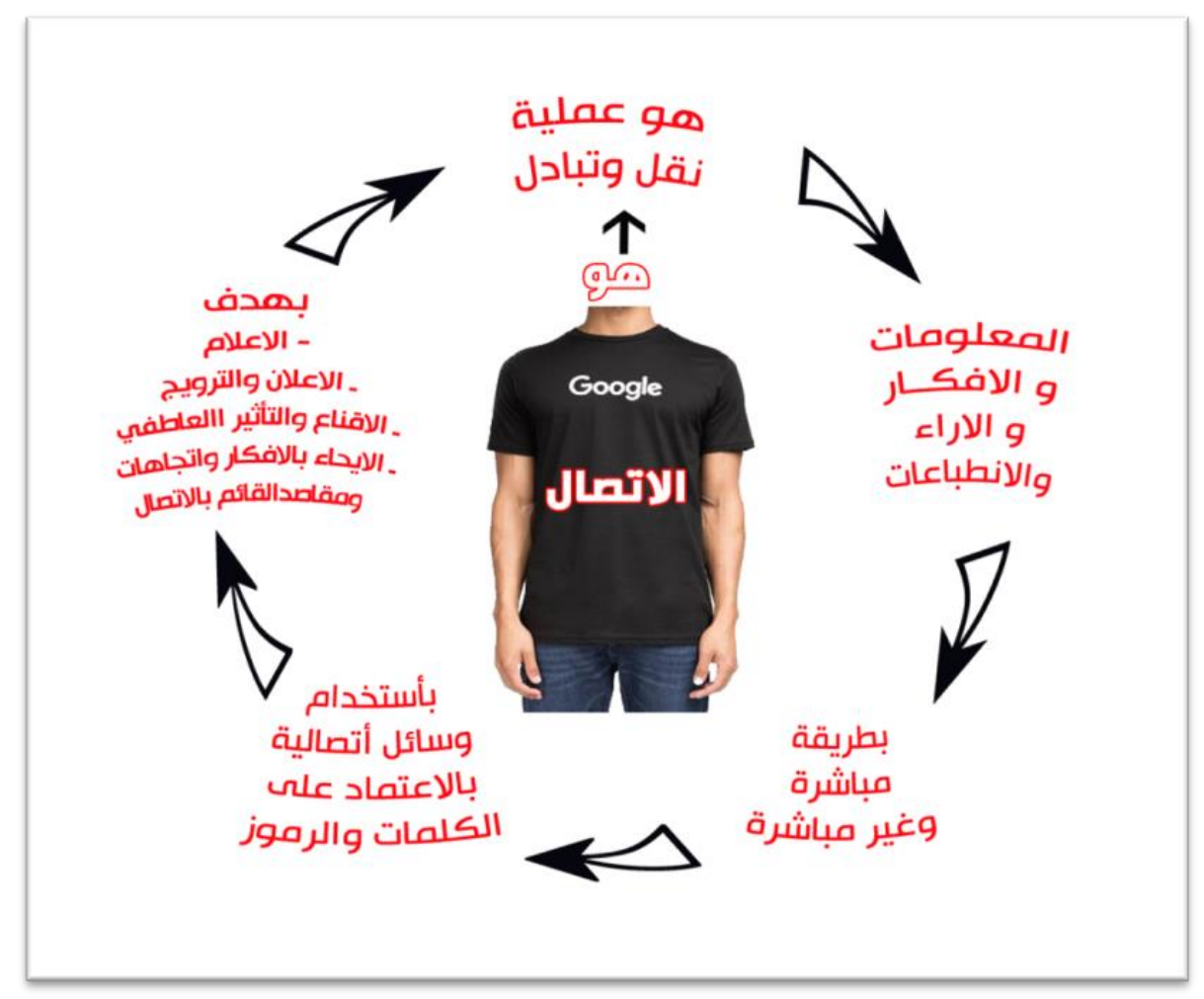

مخطط رقم ( 3 ) يمثل المخطط ملخص مفهوم الاتصال 
ان وسائل الاتصال ومنها الملصق و الإعلان ومنها اقمشة الملابس المطبوعة و التي تؤدي دوراً هاماً في المجتمع توجيهاً وإرشاداً تبني علاقة حتمية بين أفر اد المجتمع ومن مختلف

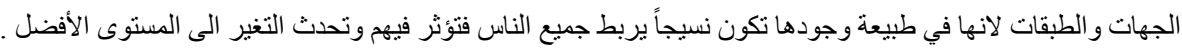

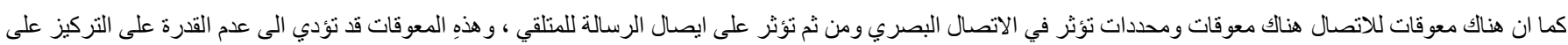
الفكرة التصميمية بسبب عو ائق قد تكون بيئية ، أب تتعلق بالبيئة الخارجية من الضوضاء او قد تكون بسبب طريقة العرض وسوء التنظيم فعملية عرض الملصقات المكتظة بعضها فوق بعض تؤدي الى التشويش اذن يتعذر الاتصال البصري بسبب عو ائق اساسية تحول دون الاتصال الفعال وعدم ادر اكت محتوى الرسالة التي يهذف الى ايصالها المصمم اما بسبب مضمون الفكرة او الوسيلة التي

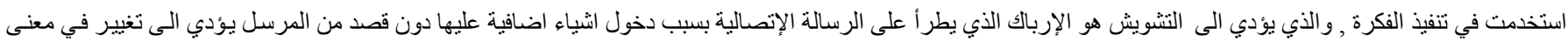
الرسالة او عدم فهمها فهماصحيحا، ويشير النشويش الداخلي الناشيء عن التوظيف الغير صحيح في طريقة عرض الصور والرسوم او في توظيف قيم لونية ذات تردد موجي عالٍ او او

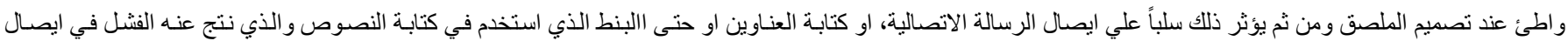

الفكرة التصميمية او قد يكون سوء الطباعة او نوعية الورق المستخدم ، فان تشويش المعنى، يعني عدم القدرة على تفسيراً الرسالة تفسير صحيحاً فيفهمها المستقبل فهماً خاطئًاً . وبذلك ان عدم وضوح الرؤيا يؤثر سلباً في الاتصال البصري ، ومن ثم تضعف الفكرة التصميمية وتعوق الاتصال البصري الذي يؤئثر فئر في ايصال الفكرة وعدم القدرة على التركيز بسبب الاهتمام باكثر من امر واحد وفي آن واحد في المجال نفسه مما يعيق الاتصال ويعرقل وصولهُ بوضوح الى المتلقي ، او بسبب طريقة العرض غير المنظم مما يؤدي الى تشويش المتلقي و عدم فهمهِ.

2-3-2 شروط الاتصال :-

للاتصال شروط يلخصها الباحث بالمخطط رقم (4) :-

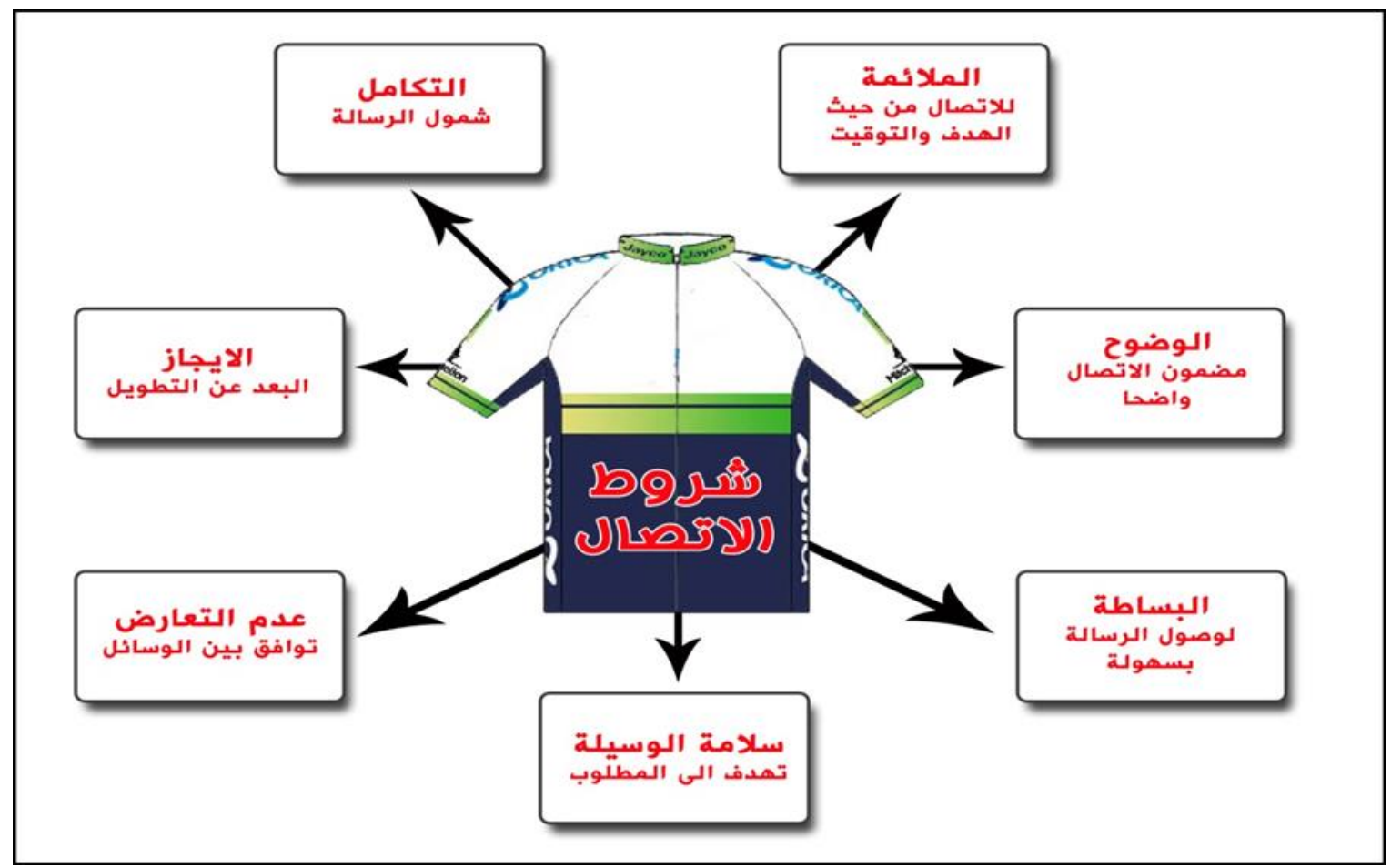

مخطط رقم (4) المخطط يمثل الثروط الأساسية للأتصال

3-3-2

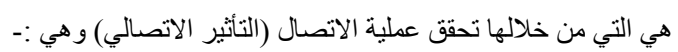
1- المرسل (المصمم) : و هو القائم بالعملية الاتصالية ويعتبر "صاحب الفكرة التي لا بد أن تكون واضحة في ذهنه أو لاً ويحسن التعبير عنها، وأن بر اعي طبيعة الوسيلة التي

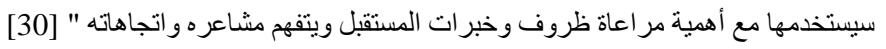


Oday Ismael Ibrahim, Journal of Techniques, Vol. 2, No. 3, September 30, 2020, Pages 28-43

الرسالة (الفكرة او المضمون): وهي المر اد توصيلها إلى المتلقي، فهي " جو هر عملية الاتصال، لذا يجب أن تصـاغ بطريقة يفهها المتلقي، وهذا يتطلب در اسـة الجمهور

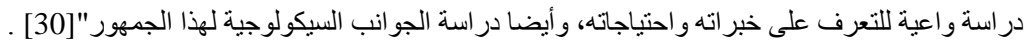

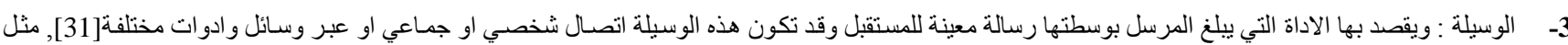

(الاقمشة والأزياء).

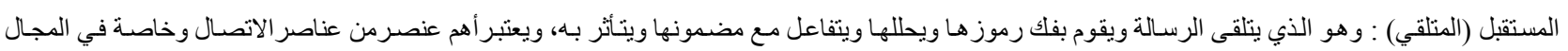
الإعلاني " و هو ليس مجرد حاصل جمع عدد من الأفر اد، لكنه جماعة ما تجمع بين أفر ادها خبر ات مشتركة، وظروف حياة معينة، وان كانت هناك اختلافات كثيرة بين

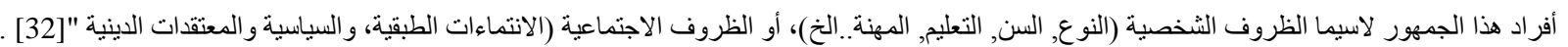
التغذية الر اجعة : و هو ما يسميه البعض (التغذية المرتدة) والمر اد به هو رد الفعل من قبل (المتلقي) نتيجة لتعرضه للرسالة ومدى استجابته لها " فالمرسل (المصمم) حين $-5$

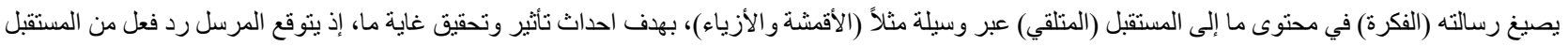

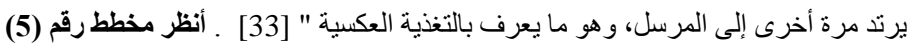

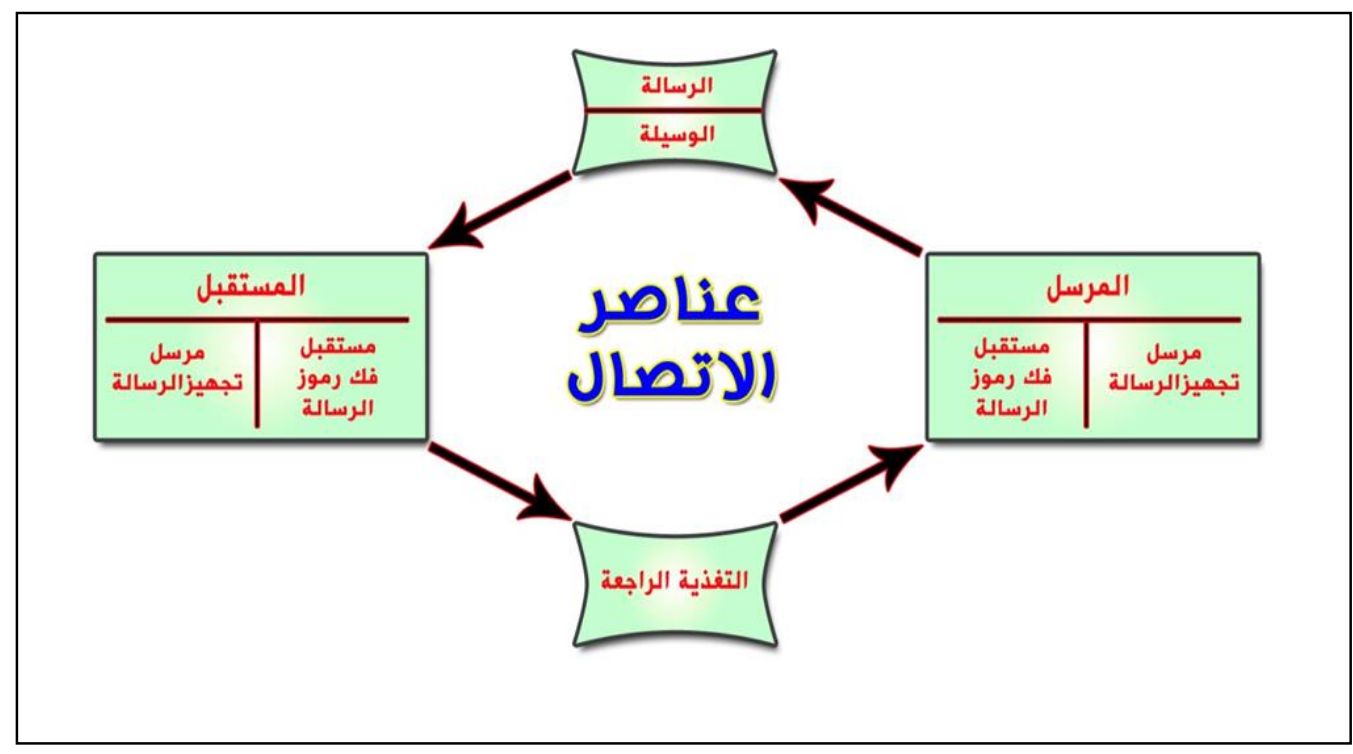

مخطط رقم ( 5 ) المخطط يمثل تلخيص لعناصر الاتصال

4-3-2

تعتبر اللغة البصرية من عناصر الاتصال البصري ومفرداتها بصورة عامة هي (الثكل اللون و القيمة الضوئية والحجم والحركة و الفضـاء) وغير هـا من الصفات المظهرية

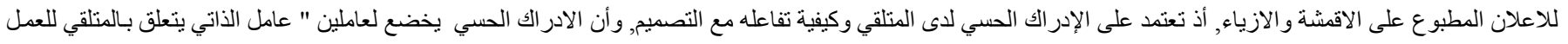
الفني بميوله الخاصة و استعداداته العامة وخبرته السابقة. و الثناني عامل موضوعي يتعلق بالثيء المدرك (التكوين التصميمي )، فالعالم المحيط بالمتلقي عالم لـه قو انينها ويسير وفق نظام

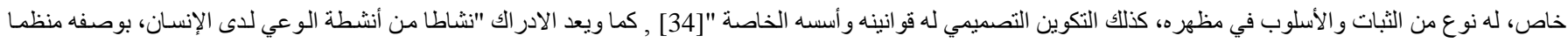
للمعلومات ولر غبته في تفسير الأشياء والظو اهر المحيطة بـه, و هو يمثل عملية تفاعل بين الفرد وذاته وبين بيئته بما فيها من عناصر ، بـاختلاف المستوى الإدر اكي الحسي العقلي ، الجمالي " [35]،

ويرى الباحث بإن المصمم يتعامل مع الظو اهر والعو امل التي تتحكم في المجال الإدر اكي بوصفها مدخلا أساساً للوعي بطبيعة الرسالة الاتصالية (الجمالية) ومدى فاعليتها في

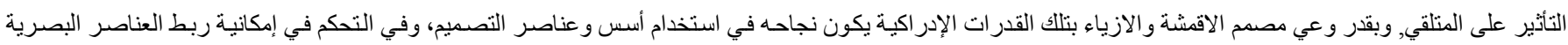
وتحقيق اكبر قدر من اتساق الاعلان والأشكال في التصاميم ذات البعدين و الثناث ابعاد, وجعل الاعلان المطبوع على الاقمشة و الازيـاء يؤدي الوظيفة ويحقق الجمالية و المنفعة للجهه

المروجه

وتلعب المؤثرات البصرية في الاعلان المطبوع على الاقمشة والازياء دوراً تشويقيًا عند المتلقي, فهي تزيد من جذب البصر و الجمالية وترفع من قيمة القماش وبنفس الوقت

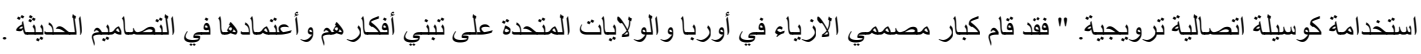

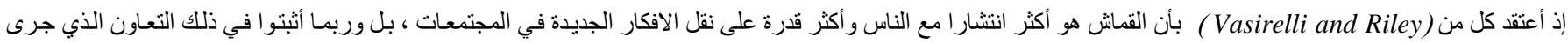

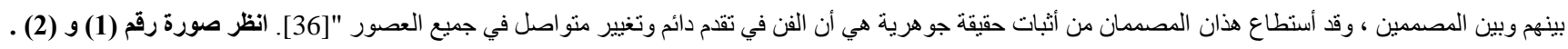




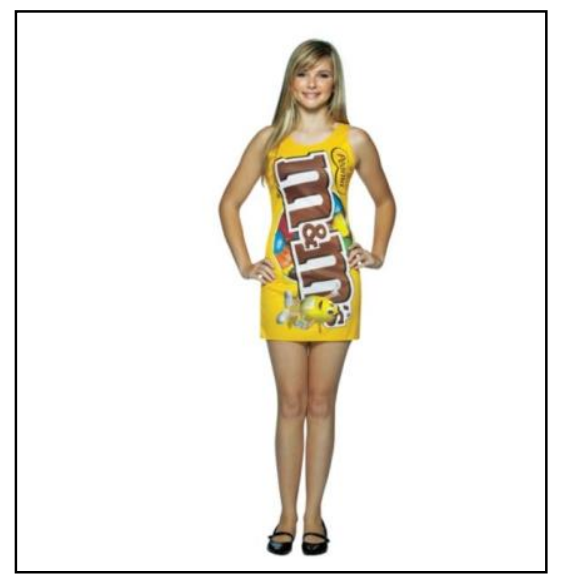

صورة رقم ( 2 ) يمثل المؤثر البصري للماركة العالمية على فضاء الفستان [38]

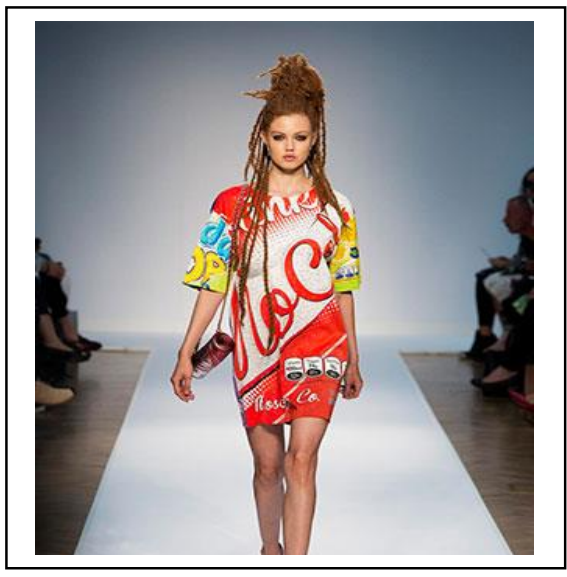

صورة رقم ( 1 ) يمثل استخدام الفستان النسائي كوسيلة اعلانية أتصائية [37]

ومن خلال ما ذكر يرى الباحث أن للمؤثرات البصرية لها قيمة كبيرة على الزي فهي تزيد من جماليتة وتجذب النظر وتجعل من الزي كوسيلة متحركه تجذب عين المتلقي للفكرة او التصميم المطبوع على الاقمشة والازياء مما يجعل للمؤثرات الصورية اهمية كبيرة تستخدم في فضاء بنية الزي وجعله وسيلة اعلانية ترويجية .

5-3-2 الادراك كنظام أتصال :-

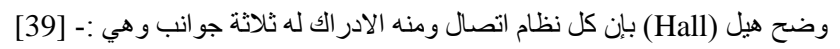

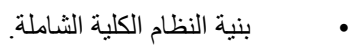

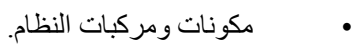

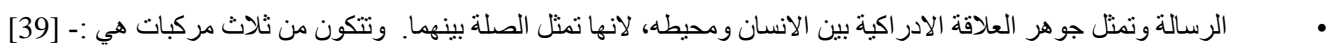
• المجاميع : هي ما ندركه او لاً. • المفردات : هي المكونات التي تشكل وتحضر المجاميع. • الانسـاق : هي اساليب تنظيم المجاميع وتجميعها سوية لاعطائها معنى . والمخطط التالي رقم ( 6 ) يوضح مكونات العملية الادر اكية كنظام اتصال

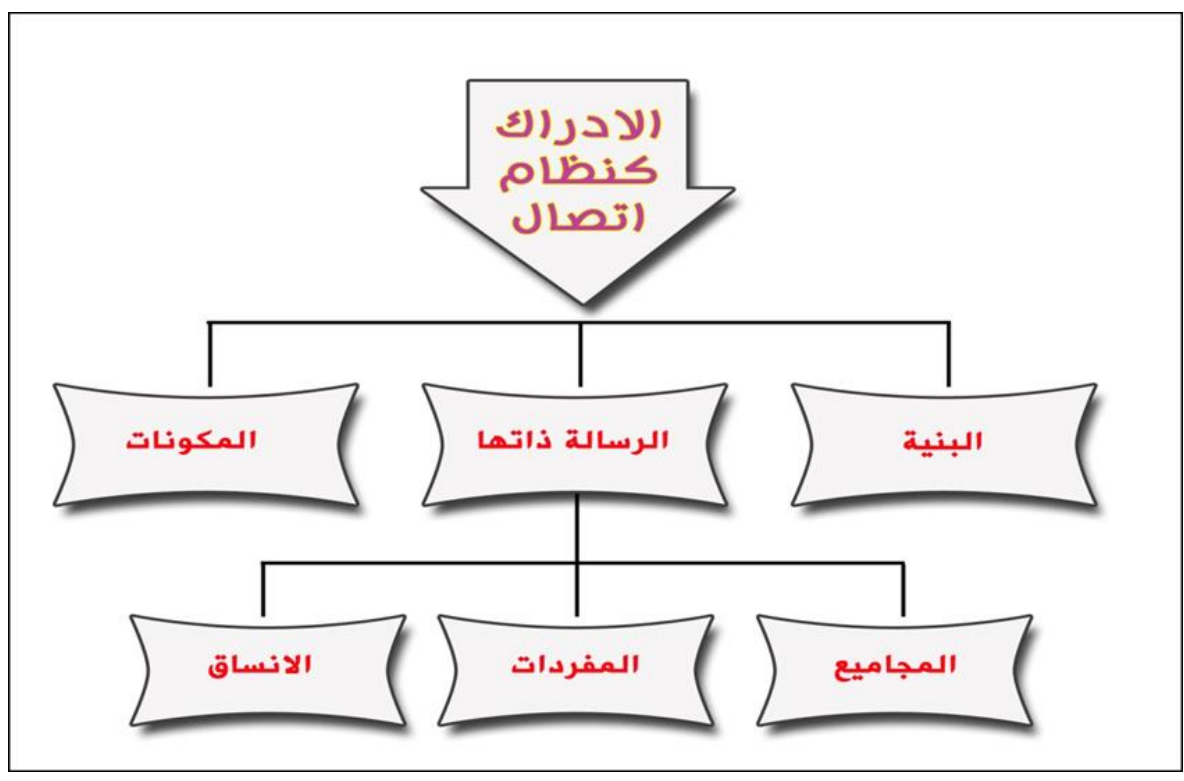

مخطط رقم (6) المخطط يمثل الادراك كنظام أتصال وأهم العلاقات الادراكية للأنسان مع محيطة 
1. بعتمد الأعلان على أسلوب مخاطبة يهدف استثارته المتلقين, برسالة مدروسة على اسس علمية وعلية , فضلاً عن تحقيق الوظيفة و الفاعليه وباستخدام وسـائل اتصـال مختلفة

كالاقمشة والازياء,

تمثل العناصر التصميمية المكون الأساسي لبناء الاعلان على بنية الزي وخامته، ويعد الحرف سواء كان (عربياً أو لاتينياً) اهم العناصر التبيو غر افية, أذ يتشكل بتشكيلات تصميمية,

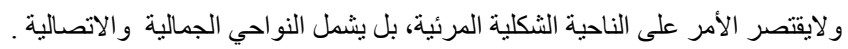

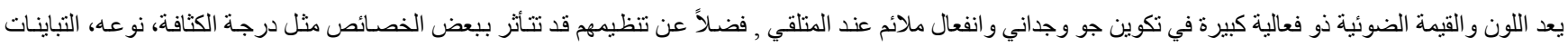

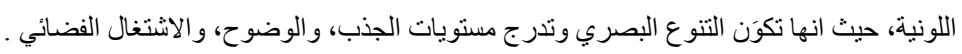

للأسس التصميمية دور مهح وبارز، كونها تقوم بتنظيم جميع الوحدات والأجزاء الداخلة في العمل التصميمي الأعلاني على أقشة الازياء المطبو عةد، مما تعمل على تماسك ووحدة

أن كل فضاء الزي هو منطقة اعلانية وأن مصمم الاقمشة والازياء هو الادرى بينية الزي من نسبة وتناسب و الحجوم, وأختيار المكان الانسب لثكل الاعلان المستخدم على الاقمشة

تحقق التقنية المستخدمة في الاعلان المطبوع على الاقمشة والازياء الهدف و الغاية بالانجاز التام لمادية الفكرة التي تمت صياغتها ومن ثم إنشاؤها على بنية الزي. يمكن إنشاء الحركة أدر اكية بصرية تشويقية داخل فضاء بنية الزي بطريقة ديناميكية تسـاهم في تنقل العين بطريقة مدروسـة. وذلك من خلال تنظيم العناصرو الاسس التصميمية للاقمشة و الازياء المطبو عه .

تلعب أرضية بنية الزي (فضاء القماش) دور انشيطا في مجال الادر اك البصري, كما أن أطار الصور لا يعمل على وجود مكون تصميمي (الاعلان) الا في فضاء معين, حيث تمثل

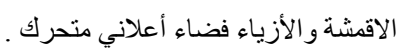
تحقق المؤثر ات البصرية قيمة كبيرة في تصاميم الاعلانات الترويجية على الاقمشة والازياء, فهي تزيد من جمالية التكوينات المطبوعة ضمن فضاء الزي بالأضافة الى جذب عين

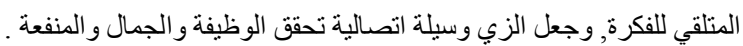
تؤثر البيئة و المجتمعية في ابتكار تصاميم أعلانية مطبو عة على أقمشة الأزياء, فضـلاً عن أستخدام الالوان و الرموز وبحسب البيئة الاجتماعية بحيث لا تعارض عادات وتقاليد المجتمع المقصود بالاعلان .

اعتمد المنهج الوصفي في تحليل العينة، بوصفه المنهج الملائم لطبيعة البحث وللوصول الى تحقيق هدفه.

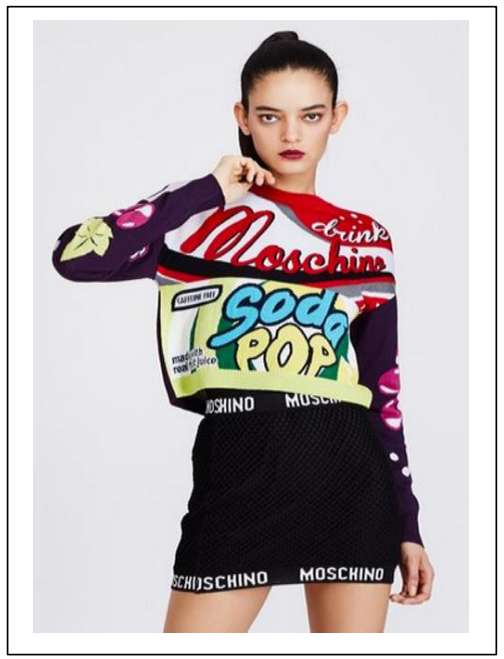

تم اعتمادعينة قصدية، اختير منها (3) نماذج تخدم أهداف الدراسة.

0




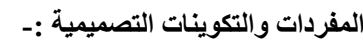

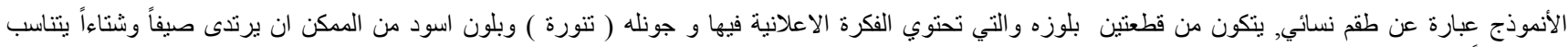

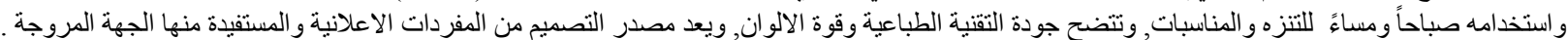

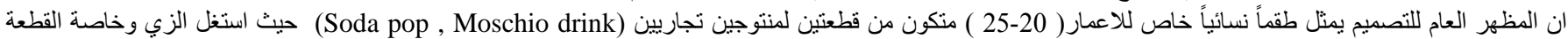

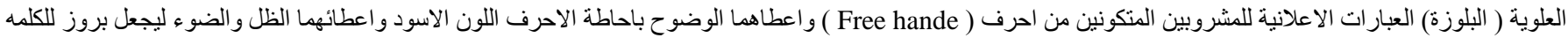

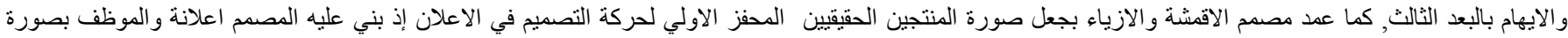

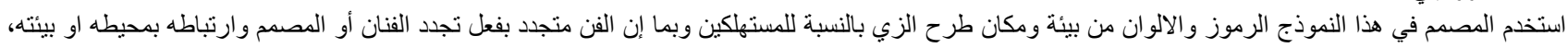

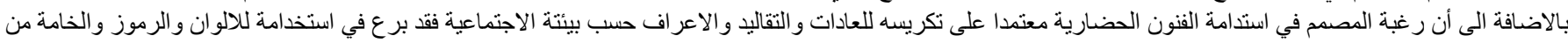

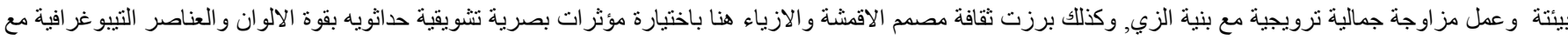

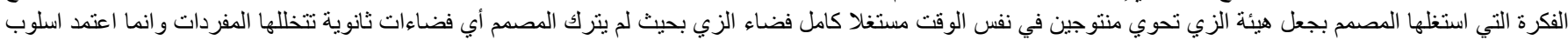

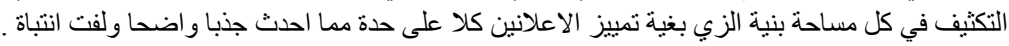

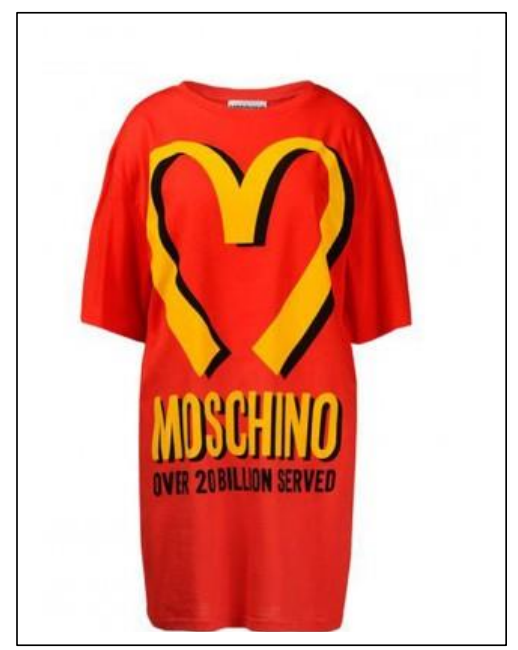

[411 [2) عينة التحليل رقم
(2) 2-3-4 عينة رقم

الوصف العام :

الأداء الوظيفي للزي : فستان نسائي.

جهة الاعلان : MOSCHINO

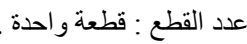

التقنبات الاظهارية : طباعة 3 - dمكملات اظهارية.

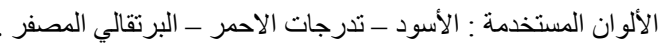

المنشأ : مبلانو - ابطاليا

سنة الصنع : 2015

المفردات والتكوينات التصميمية :-

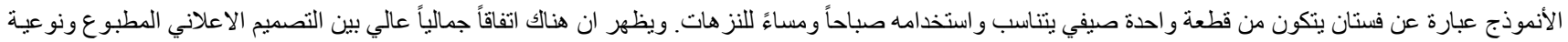

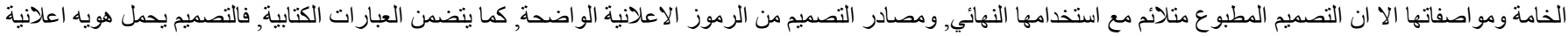

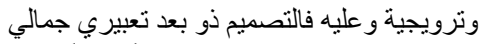

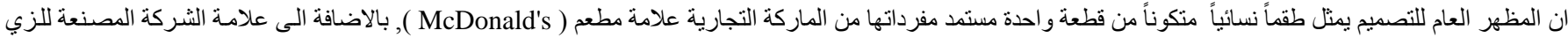
والعبار ات (MOSCHINO)

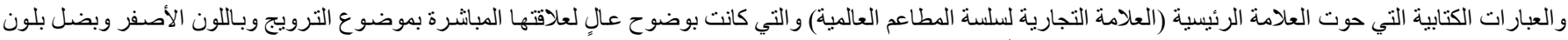

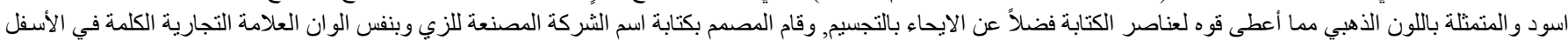

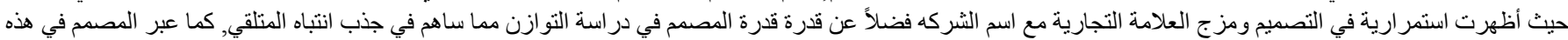

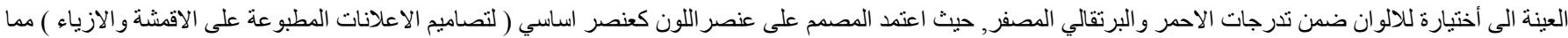

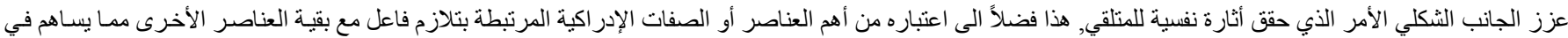

تكوين الهيئة المرئية .

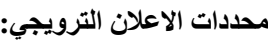

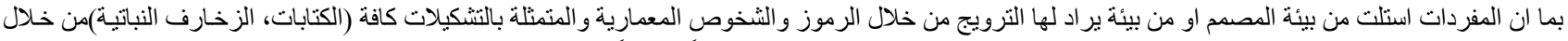

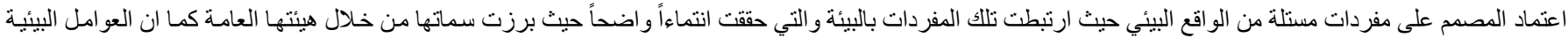

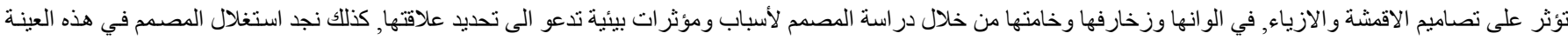

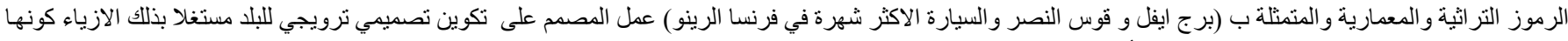

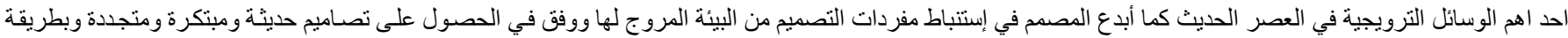

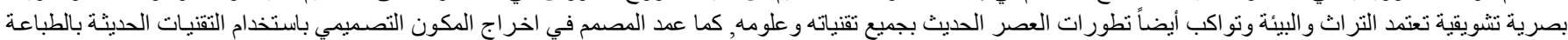

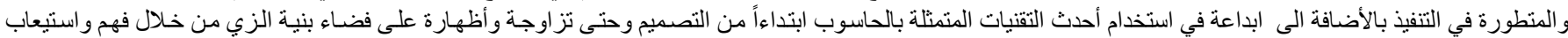

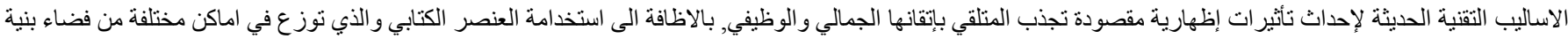
الزي مع اظافة المكملات التزيينية للعناصر الكتابية كما نجد أن الزي ينخذ شكله من عناصره المتعددة كوسيلة للترويج الاعلاني. 


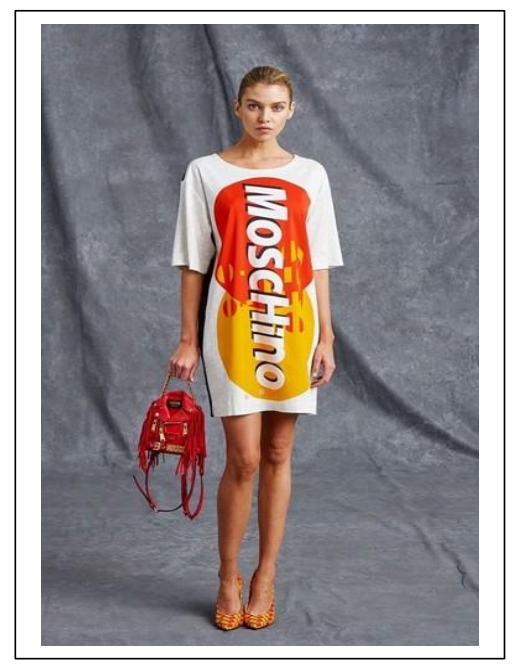

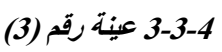

الوصف العام :

الأداء الوظيفي للزي: فستان نسائي.

جهة الاعلان. MOSCHINO

عدد القطع: قطعة واحدة.

التقنيات اتنفيذية : طباعة السكرين .

الألوان المستخدمة : البرتقالي المصفر ـ الاحمر ـ الابيض . لئل

المنشأ: ابطاليا

سنة الصنع:

عينة التحليل رقم (3) [42]

المفردات التصميمية :-

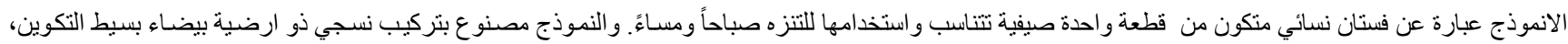

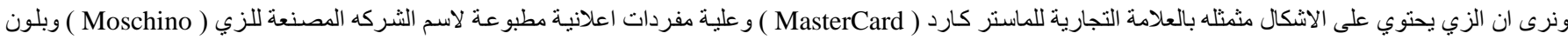

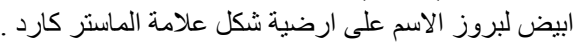

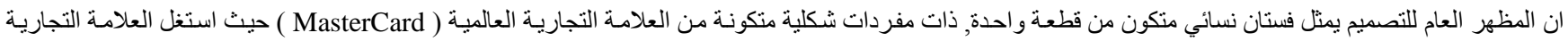

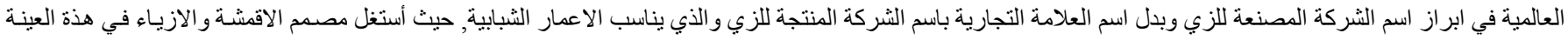

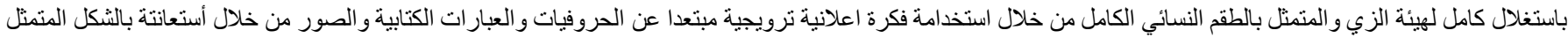

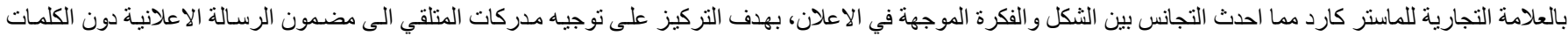

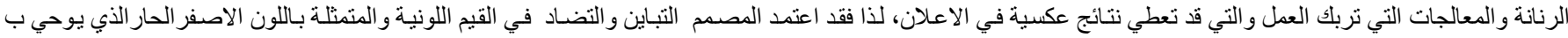

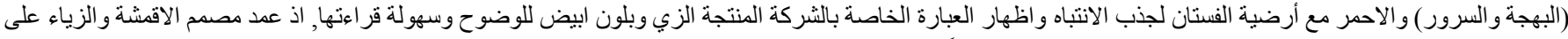

إظهار فعالية الانسجام و التضاد اللوني و الثكلي لكسب جذب النتباه, فضلاً عن القيم الضوئية التي التعد التبان احد عو امل تعزيز الثكل, و التي تعد من اساسيات نجاح الاعلان في هذه العينة .

مؤثرات ومحددات الاعلان الترويجي :-

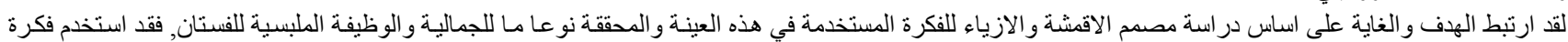

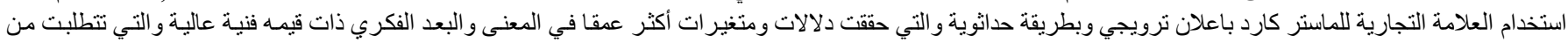

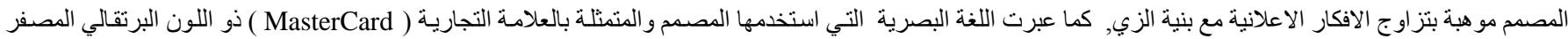

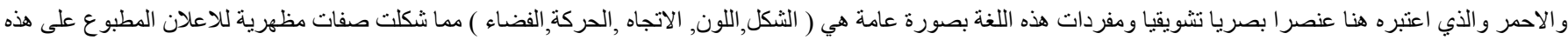

توصل البحث الى عدة نتائج و كالآتي :-

1- ادى استخدام العناصر التصميمية وتشكل الحروف و الذي ظهر و اضحاً في جميع النماذج التى تحقيق عامليّ التتابع البصري و الاستمر اريـة واحداث الابهام بالعمق الفضائي .

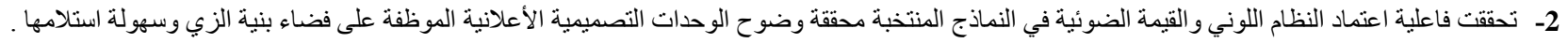

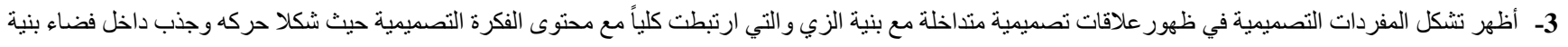

الزي.

4- اظهرت الطبيعة التصميمية بعداً جمالياً من خلال العلاقة بين مفردات الاعلان و بنية الزي وذلك من خلال حالة الوعي وثقافة مصمم الاقمشة والازياء, وتفاعل العناصر

الداخلة بالتصميمات مع المكملات التزيينية حقتت تر ابطا جماليا ووظيفيا وترويجيا .

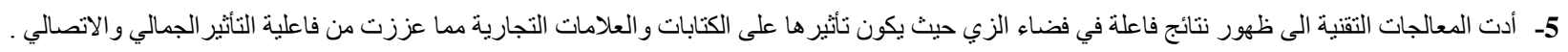
6- برزت فكرة مصمم الاقمشة والازياء الذي هو جزء من المجتمع المقصود بالأعلان وينتمي الى مرجعياته الثقافية والاجتماعية، فالمصمم عن (المكان) باختيار الرموز

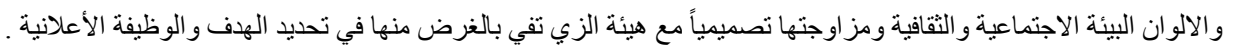


1- أستخدام الخامات ذات المميز ات الخاصة في إظهار طباعة الاعلان عليها، من حيث نصوع وثبات الالوان, و إبراز الجوانب الجمالية والوظيفية التي تلائم تقنيات الطباعة . 2- ان للعناصر و الأسس التصميمية دورا فاعلا من الناحية الجمالية والوظيفية، من خلال التتوع في المحتوى الأعلاني التصميمي، كما وظهر الاعتماد على فاعلية الايقاع و السيادة بهدف تحقيق التماسك والترابط والجذب. كذلك وظف التباين اللوني بتأثير ات قصدية ايجابية لتحقيق الثد البصري وإظهار الجاذبية للاعلان محققا حركه داخل فضاء بنية الزي . 3- ظهرت قدرة مصمم الاقشة والازياء في بناء موضوع الاعلان وتجسيده على فضاء بنية الزي، وذلك لألمامه بالاطر الموضوعية (الفكرية) والتقنية (الاخر اجية) ودوره في

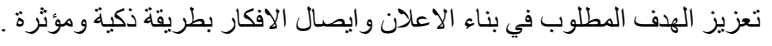

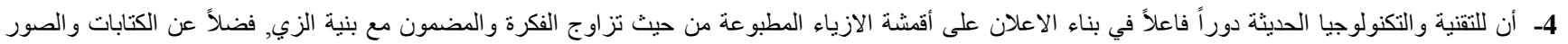

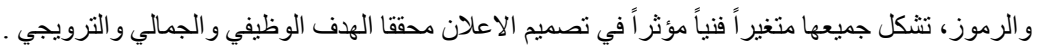
5- و علاقه الأعلان المستخدم مع بنية الزي من حيث الموضوع و الأبعاد والقيمة واللون إستتباط المفردات الأعلانية من البيئة المقصودة بالاعلان وعلى الاقمشة والازياء

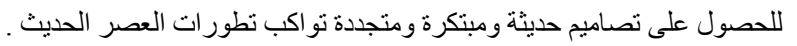

لغرض تحقيق الهدف الثاني للبحث بوضع اشتراطات (مرتكزات) تصميمية تسهم في تحقيق الفكرة والبعد الجمالي والوظيفي والترويجي للاعلان المطبوع على أقشة الازياء.

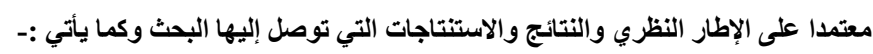
1 الاعلان بحقق قيمة متفردة وعلامة مميزة في تطور الثكل التصميمي للاقشة والازياء عبر منظومات التكوين وبطريقة حداثوية مستحدثة في تصميم اقشة الازياء 2) المؤثرات البصرية و التصوير الفوتوغر افي و التصميم الرقمي دور مهم, فهي تزيد من جمالية الاعلان المطبوع على الاقمشة والازياء وتعطي بعداً تشويقيًا, فهي تجذب عين المتلقي للتكوين التصميمي . 3) توجيه العناصر التصميمية والتيبوغر افية للأعلان من قبل مصمم الاقمشة والازياء فهو الادرى والاعرف بفضاء بنية الزي وبطريقة ينتج عنها حركة بصرية (تنشط داخل

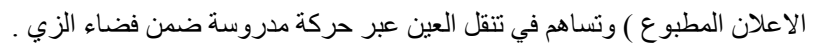
4) اظهار الاثارة و الثد و التركيز نحو شكل أو اسم المنتوج وبالمكان المناسب على بنية الزي, فضلاً عن أن ناتج الأظهارات الأبنكارية والابداعية للأعلان على أقمشة الازياء المطبو عة من صنع مخيله وفطنه مصمم الأقشة و الازياء . 5) أستخدام التكنلوجيا الحديثة في تصاميم الاعلان المطبوع على الاقمشة والازياء, من شأنه أن يعزز من قيمة الزي الجمالية والوظيفية والترويجية, و النقطة الاساس في هذا الموضوع هو لتحقيق : أحداث الجذب , أحداث لفت أنتباه , احداث الترويج . 


\section{References : -}

[1] Glossary of the Holy Qur'an, The Arabic Language Academy, Volume II, 2nd Edition, The Egyptian Public Authority for Authoring and Publishing, 1971, p. 13.

[2] Rosenthal, b. Yudin, The Philosophical Encyclopedia, Translated by Samir Karam, Dar Al-Tale'ah Publishing, 1st Floor, Beirut, 1974, p. 259.

[3] Sabat, Khalil: The Declaration, Its History, Foundations, Rules, Art, Ethics, 1st Edition, The Anglo-Egyptian Library, Cairo, 1969, p.32

[4] Fahad Salim Al-Khatib, Muhammad Suleiman. Marketing principles are basic concepts. Al Yazourdi Scientific House for Publishing and Distribution. Amman, I. 1. 2000, p. 155.

[5] Dreams of Mohamed Gerges. Educational-learning design for using persuasive theories to develop the skills of students of the Faculty of Applied Arts in the art of advertising. Thesis submitted to the College of Fine Arts, University of Baghdad. Unpublished. 2013. p. 18.

[6] Al-Ansari, Jamal Al-Din Bin Muhammad. Arabes Tong. Cairo. Egyptian House for Printing and Translation. B. T. P. 79.

[7] http://kenanaonline.com/users/raniaFashion/posts/112843

[8] Al-Sahn, Muhammad Farid. Advertising. University House for Printing and Publishing, Alexandria. I 1. P. 14.

[9] Al-Ani, Hind Muhammad Sahab. Aesthetic values in designs of children's fabrics and costumes and their dialectical relationship. Baghdad University. College of Fine Arts. PhD thesis. Unpublished. 2002. p. 27.

[10] Samir Muhammad Hussein: The Art of Advertising, Cairo, 1977, p. 13.

[11] Ellen Lupton, Thinking With Type, Princeton architectural press, new york, 2004. p: 21.

[12] Marwa Mohamed Kamal El-Din, The Future of Digital Newspaper Printing, The Egyptian Lebanese House, Egypt, 1st Edition, 2007. P.102.

[13] Al-Hussaini, Haider Hashem. Setting design bases to enrich artistic taste in modern women's textile designs. Baghdad University. College of Fine Arts. Master Thesis. Unpublished . 2009. p. 12.

[14] Knowledge World Series. Aesthetic preference (studies of artistic cognitive psychology). Issue (267). Al-Watan Printing Press. Kuwait. 2001, p. 266.

[15] Al-Hussaini, Haider Hashem. Setting design bases to enrich artistic taste in modern women's textile designs. Baghdad University. College of Fine Arts. Master Thesis. Unpublished . 2009. p. 12.

[16] Layla, Yaghi. Textiles and fashion design. Al-Quds University Publications. Oman. I 1. 1995. p. 49.

[17] Ismail Shawky: Art and Design, Faculty of Art Education, Helwan University, 1999. P. 230.

[18] Al Amri, Faten Ali Hussain. Integration of fabric designs, fashion and resulting relationships in the overall achievement. Baghdad University. College of Fine Arts. PhD thesis. Unpublished. 2005 m. P. 55.

[19] Al-Ani, Hind Muhammad Sahab. Aesthetic values in designs of fabrics and costumes for children and their dialectical relationship. Baghdad University. College of Fine Arts. PhD thesis. Unpublished. 2002. p. 40.

[20] Adly Muhammad Abdul-Hadi, and Al-Daraiseh. Muhammad Abdullah. Design principles. Arab Society Library for Publishing and Distribution. I 1. 2009 m. P. 125.

[21] Al-Musawi, Asaadati. Formal formation systems and demonstration techniques in men's fabric designs. Baghdad University. College of Fine Arts. Master Thesis. Unpublished . 2014. p. 23.

[22] Al-Ani, Hind Muhammad Sahab. Aesthetic values in designs of fabrics and costumes for children and their dialectical relationship. Baghdad University. College of Fine Arts. PhD thesis. Unpublished. 2002. p. 45.

[23] Rob Carter, Digital color and Type, roto vsion sa, sales \& production office Sheridan house, uk, 2002.p: 188.

[24] Ismail Shawky: Art and Design, Faculty of Art Education, Helwan University, 1999, p. 225. 
[25] Shaker Abdel Hamid Abdel Hamid, Visual Arts and the Genius of Perception, 1st Floor, The Egyptian General Book Authority, Cairo, 2008, p. 164.

[26] Al-Haiti, Hadi Numan. Communication and cultural change. Little encyclopedia. Baghdad. Publications of the Ministry of Culture. 1978. p. 13.

[27] Al-Abyari, Fathi. Global media and advertising. Alexandria. University Knowledge House. 1985. P. 15.

[28] Ibrahim Fathi, Dictionary of Literary Terms. Arab Foundation for United Publishers. Tunisia. P. 36

[29] Mahmoud Hassan Ismail. Principles of communication science and influence theories. Egypt. International House for Publishing and Distribution. I. 1. 2003. p. 21.

[30] Mahmoud Hassan Ismail. Principles of communication science and influence theories. Egypt. International House for Publishing and Distribution. I 1. 2003. P. 95.

[31] Samia Muhammad Jaber. Communication and modern society (theory and practice). Cairo. Knowledge House. 19820 p. 99.

[32] Laila Abdul Majeed. The Egyptian public and communication policy. Egypt. National Center for Social Research. 1983, p. 30.

[33] Mahmoud Khalil and Mohamed Mansour. Media language production in informational texts. Egypt. Cairo University. 1999 p. 154.

[34] Abu Jad, Hassan Ezzat. Visual phenomena and interior design. Printed on Sunday. Beirut. 1971, p. 100.

[25] Al-Hussaini, Haider Hashem. Setting design bases to enrich artistic taste in modern women's textile designs. Baghdad University. College of Fine Arts. Master Thesis. Unpublished . 2009. p. 40.

[36] Roya Yassin Hamid. Modernist modeling in the design of contemporary fabrics and fashion styles. PhD thesis. Baghdad University. College of Fine Arts. Unpublished. 2014. p. 98.

[37] [38] https://www.hungertv.com/feature/top-ten-andy-warhol-inspired-collections/

[38] http://pokershrink.blogspot.com/2011/02/m-monday-clothing.html

[39] Al-Talbi, Raed Abdul-Jabbar. The effect of cognitive factors on internalization of space design. Unpublished Master Thesis, College of Engineering, University of Baghdad. 199 p. 19.

[40] https://cdn.firstwefeast.com/assets/2015/01/11.jpg

[41] https://www.pinterest.com/pin/401664860496231809/?autologin=true

[42] https://www.vogue.com/fashion-shows/resort-2016/moschino/slideshow/collection\#6 